\title{
Influence of process parameters on punch force evolution in deep drawing process
}

\author{
Wenyu Ma, Fengqin Wang, Lin Zhao, Xibang Zhang, Ziying Liu \\ Shougang Research Institute of Technology \\ Beijing, China; \\ Email: wymaustb@163.com (Wenyu Ma)
}

Keywords: finite element method; hot drawing; analysis of variance; analysis of mean

\begin{abstract}
In order to obtain a deep understanding on the influence of process parameters on punch force evolution during deep drawing of AA6111 sheet at elevated temperatures, the design of experiment (DOE) and analysis of variance (ANOVA) were employed. The process parameters analyzed in this paper are forming temperature, punch velocity, blank holder force and friction coefficient, which are major factors analyzed in many papers. The influence of process parameters on maximum punch force was quantified. The results were transferred to sound against noise ration to get a better robustness. According to the results of ANOVA, it is illustrated that the initial forming temperature has major effect (60.28\%) on the maximum punch force, and the punch velocity shows a least effect, the value of that is about $1.6 \%$.
\end{abstract}

\section{Introduction}

The application of lightweight material in the automotive vehicles is a significant way to reduce the emission and improve the fuel efficiency [1-4]. At the same time, aluminum alloys are increasingly used cars, in order to reduce the weight, and then it is helpful for the environmental preservation [5-6]. Mostly, the aluminum alloys are manufactured at room temperature, however, the ductility of aluminum alloys is not high. At the same time, the springback of the cold formed blank would lead to a bad dimension accuracy [7]. By comparison, during the hot stamping process, the blank is formed at elevated temperature, so the ductility of blank can be improved to form the complex parts $[1-2,8]$. Meanwhile, the stamping can be very efficient, as the punch velocity can be very high, so the stamping operation would be finished in a short period. [8-9].To obtain a successful part at a low cost in terms of hot sheet forming process, much research has been conducted to gain a deep insight into this complex forming technology [10-11]. At the same time, more effort is need to be done to enrich this field. Then, in this paper, the effect of forming process parameters on punch force in deep drawing process at elevated temperatures has been investigated. At the same time, the effect measured has been quantified using statistical method.

\section{Test Design}

There are many variables in forming process affecting the forming quality of the final products. This study aims at getting a deep understanding on the relationship between process variables and product quality. The relatively flexible parameters are process parameters listed as BHF, punch velocity, friction coefficient and the initial forming temperature of blank. These parameters play a significant role in the quality of forming process. So those process parameters are under consideration in this study. [12]

These parameters have three levels, e.g. high, middle and low. In order to avoid the artificial system error, the value for each level was selected by random. The process parameters and the corresponding levels are given in Table 1. 
Table 1 Process parameters and the corresponding levels

\begin{tabular}{llll}
\hline Process parameter & Level & & \\
\cline { 2 - 4 } & 1 & 2 & 110 \\
\hline Punch velocity $(\mathrm{V})(\mathrm{mm} / \mathrm{s})$ & 200 & 2 & 3 \\
BHF $(\mathrm{kN})$ & 1 & 0.1 & 0.2 \\
Friction coefficient $\left({ }^{\mu}\right)$ & 0.15 & 500 & 450 \\
Initial temperature $(\mathrm{T})\left({ }^{\circ} \mathrm{C}\right)$ & 550 &
\end{tabular}

In terms of four parameters and three levels for each parameter, the Taguchi orthogonal arrays are used for efficiency. According to the design principle, the L9 is employed aiming to obtain a large amount of information with a few numbers of runs. The orthogonal array is given in Table 2 .

\section{FE model for deep drawing}

The FE model for hot deep drawing includes punch, blank, die and blank holder. Due to the symmetry of the model, only a quarter was used. The geometry dimensions are listed as follows. The punch diameter is $50 \mathrm{~mm}$, the punch corner radius is $5 \mathrm{~mm}$, the die diameter is $54.4 \mathrm{~mm}$ and the die corner radius is $13 \mathrm{~mm}$. At the same time, the blank thickness is $2 \mathrm{~mm}$. The diameter of the blank is $100 \mathrm{~mm}$. And other thermal and physical properties used in FE model are shown in Table 3.

The material used in the model is AA6111 aluminum alloy. The stress-strain relationship is given in Fig. 1 [12].The stress increases with the increase of strain rate and the decrease of the forming temperature.

Table 2 Orthogonal array (L9) of Taguchi method

\begin{tabular}{|c|c|c|c|c|}
\hline \multirow[t]{2}{*}{ Experiment } & \multicolumn{4}{|c|}{ Parameter } \\
\hline & $\mathrm{V}$ & BHF & $\mu$ & $\mathrm{T}$ \\
\hline 1 & 1 & 1 & 1 & 1 \\
\hline 2 & 1 & 2 & 2 & 2 \\
\hline 3 & 1 & 3 & 3 & 3 \\
\hline 4 & 2 & 1 & 2 & 3 \\
\hline 5 & 2 & 2 & 3 & 1 \\
\hline 6 & 2 & 3 & 1 & 2 \\
\hline 7 & 3 & 1 & 3 & 2 \\
\hline 8 & 3 & 2 & 1 & 3 \\
\hline 9 & 3 & 3 & 2 & 1 \\
\hline
\end{tabular}

Table 3 Physical and thermal properties used in finite element simulations [12]

\begin{tabular}{lll}
\hline Property & Part & Value \\
\hline Density $(\mathrm{t} / \mathrm{mm} 3)$ & Blank & $2.7 \mathrm{e}-9$ \\
& Tools & $7.8 \mathrm{e}-9$ \\
Thermal conductivity $\left(\mathrm{mW} / \mathrm{mm} /{ }^{\circ} \mathrm{C}\right)$ & Blank & 167 \\
& Tools & 20 \\
Specific heat $\left(\mathrm{mJ} / \mathrm{t} /{ }^{\circ} \mathrm{C}\right)$ & Blank & $9.2 \mathrm{e} 8$ \\
& Tools & $6.5 \mathrm{e} 8$ \\
Young's modulus, E $(\mathrm{MPa})$ & Blank & 70000 \\
Poisson's ratio, v & Blank & 0.3 \\
\hline
\end{tabular}



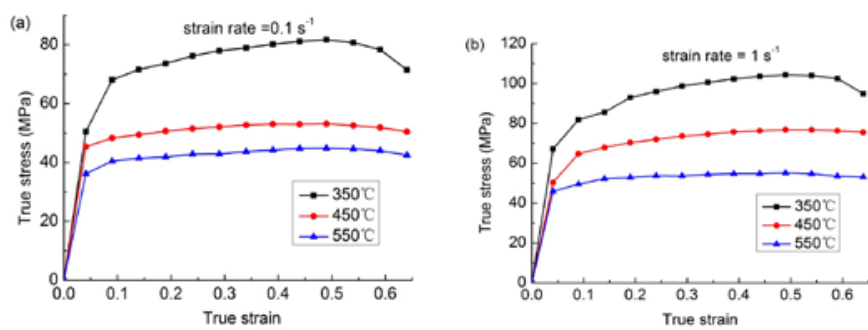

Fig. 1 True stress-true strain curves for different temperatures at different strain rates of (a) $0.1 \mathrm{~s}^{-1}$ and (b) $1 \mathrm{~s}^{-1}[12]$.

\section{Results and disscusion}

\section{Punch force evolution}

Punch froce is also a forming process characteristic that has attracted many researchers' attention. According to reference [13], the punch force $F_{p}$ is given by:

$$
F_{p}=2 \pi r_{p} t_{0} \sigma_{w}
$$

where $r_{p}$ is the punch radius, $t_{0}$ the peripheral radius of the blank. And $\sigma_{w}$ is the total stress, which includes the pure radial drawing stress on the flange, frictional radial stress at the blank-die and blank-holder interfaces, the bending stress, the radial drawing stress on the die profile, the frictional radial stress on the die profile and the unbending stress.

In consideration of the practical application, the lower the punch force, the better. In the present study, the punch force-punch stroke curves are shown in Fig. 2. Generally speaking, at the beginning of the deep drawing, the punch forces increase until they reach the maximum values and then reduce. As more material flows into the die cavity, the punch forces decrease as a result of friction reduction effect at the blank-die and blank-holder area and less increment of circumferential stress. It can be seen from Fig. 2 that low forming temperature leads to large punch force, such as case 3 and case 8. On the contrary, high temperature causes lower punch force even with middle friction coefficient or high blank holder force (case 9 and case 1). The largest maximum punch force is observed in case 3 , where low temperature, high friction coefficient and blank holder force are used.

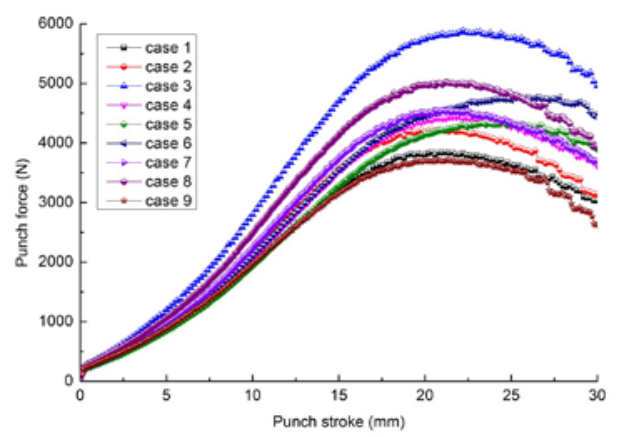

Fig. 2 Punch force evolution

\section{ANOVA and ANOM}

Taguchi's method to increase the robustness of design aims at maximizing the results' signal-noise $(\mathrm{S} / \mathrm{N})$ ratio. The $\mathrm{S} / \mathrm{N}$ ratio is obtained in two steps. The first step is to calculate the Mean Square Deviation (MSD) of results. The second step is to calculate the $\mathrm{S} / \mathrm{N}$ ratio using the MSD according to the following equation:

$\mathrm{S} / \mathrm{N}=-10 \log (\mathrm{MSD})$

The MSD mentioned above is a statistical quantity. It reflects the deviation from target value. As the lower punch force, the better. So the lower-the-better (LB) is chosen, as fllows: [12].

$\operatorname{MSD}=\left(Y_{1}^{2}+Y_{2}^{2}+\cdots+Y_{N}^{2}\right) / N$

The overall mean $\mathrm{S} / \mathrm{N}$ ratio can be calculated by the following equations

$\overline{S / N}=\frac{1}{9} \sum_{i=1}^{9}(S / N)_{i}$ 
The sum of squares according to each factor can be achieved by

$\mathrm{SS}_{i}=\sum_{j=1}^{3}\left((S / N)_{i j}-\overline{S / N}\right)^{2}$

The sum of squares based on the variation about overall mean can be expressed as $\mathrm{SS}=\sum_{i=1}^{4} S S_{i}$

The percentage contribution of each parameter on the quality characteristic can be calculated as $\%$ contribution $=100 \times\left(\mathrm{SS}_{i} / \mathrm{SS}\right)$

Table 4 Simulation results and corresponding $\mathrm{S} / \mathrm{N}$ ratio values for maximum punch force

\begin{tabular}{|c|c|c|c|c|c|c|c|}
\hline $\begin{array}{l}\text { Exp. } \\
\text { No. }\end{array}$ & $\mathrm{V}$ & BHF & & $\mu$ & $\mathrm{T}$ & $\begin{array}{l}\text { Maximum } \\
\text { punch force(N) }\end{array}$ & $\mathrm{S} / \mathrm{N}$ \\
\hline 1 & 1 & 1 & 1 & & 1 & 3845.59 & -71.69926 \\
\hline 2 & 1 & 2 & 2 & & 2 & 4229.88 & -72.526561 \\
\hline 3 & 1 & 3 & 3 & & 3 & 5888.66 & -75.40033 \\
\hline 4 & 2 & 1 & 2 & & 3 & 4445.16 & -72.957748 \\
\hline 5 & 2 & 2 & 3 & & 1 & 4359.50 & -72.788734 \\
\hline 6 & 2 & 3 & 1 & & 2 & 4774.05 & -73.577739 \\
\hline 7 & 3 & 1 & 3 & & 2 & 4548.42 & -73.157211 \\
\hline 8 & 3 & 2 & 1 & & 3 & 5024.74 & -74.022272 \\
\hline \multirow[t]{2}{*}{9} & 3 & 3 & 2 & & 1 & 3719.38 & -71.409411 \\
\hline & & & & & & $\overline{\mathrm{S} / \mathrm{N}}$ & -73.059918 \\
\hline
\end{tabular}

Table 5 ANOVA for maximum punch force

\begin{tabular}{lrrrrr}
\hline Facto & \multicolumn{2}{c}{ Average S/N by factor level $\left(S / N_{\mathrm{ij}}\right)$} & Sum of squares $\left(S S_{i}\right)$ & $\begin{array}{l}\text { \%Contributio } \\
\mathrm{r}\end{array}$ \\
\cline { 2 - 4 } & 1 & 2 & 3 & & \\
\hline $\mathrm{V}$ & -73.2087 & -73.1081 & -72.86296 & 0.06325064 & 1.632236 \\
$\mathrm{BHF}$ & -72.6047 & -73.1125 & -73.46249 & 0.37202125 & 9.600323 \\
$\mathrm{u}$ & -73.0998 & -72.2979 & -73.78209 & 1.10378314 & 28.48406 \\
$\mathrm{~T}$ & -71.9658 & -73.0872 & -74.12678 & 2.33603573 & 60.28338 \\
& & & $S S$ & 3.8750908 & \\
\hline
\end{tabular}

Then the percentage contributions of BHF, punch velocity, friction coefficient and initial forming temperature for maximum punch force are illustrated in Table 4. Table 5 illustrates the importance percentage of the different parameters have on maximum punch force. In terms of maximum punch force, forming temperature of blank has a major effect with the importance percentage contribution of $60.28 \%$ followed by the friction coefficient with a significance value 28.48\%. The influence of other parameters, such as BHF and punch velocity are nearly negligible.

\section{Conclusion}

FE model for simulations of hot cup drawing at elevated temperature were established to analyze the influence of process parameters on maximum punch force. Those tests were designed according to the Taguchi technique and the results were studied by ANOVA and ANOM. The initial forming temperature of blank has greatest effect on maximum punch force with $60.28 \%$ influence followed by friction coefficient with $28.48 \%$, BHF with $9.6 \%$ and punch velocity with $1.63 \%$. The higher the temperature, the lower flow stress of material is, so less force is needed to draw the material into die cavity. 


\section{Acknowledgement}

The authors would like to thank the kind help and guidance from Professor Jianguo Lin, Royal Academy of Engineering and Department of Mechanical Engineering, Imperial College, UK. The authors would also like to thank the nice help and instruction from Baoyu Wang, University of Science and Technology Beijing.

\section{Literature References}

[1] Ma W, Wang B, Bian J, et al. A new damage constitutive model for thermal deformation of AA6111 sheet[J]. Metallurgical and Materials Transactions A, 2015,46(6):2748-2757

[2] Ma W, Wang B, Yang L, et al. Influence of solution heat treatment on mechanical response and fracture behaviour of aluminium alloy sheets: An experimental study[J]. Materials \& Design, 2015,88:1119-1126.

[3] KIM H S, KOC M, NI J. Development of an analytical model for warm deep drawing of aluminum alloys[J]. journal of materials processing technology, 2008, 197(1): 393-407.

[4] HIRSCH J, Al-SAMMAN T. Superior light metals by texture engineering: Optimized aluminum and magnesium alloys for automotive applications[J]. Acta Materialia, 2013, 61(3): 818-843.

[5] TAKUDA H, MORIK, Masuda I, et al. Finite element simulation of warm deep drawing of aluminium alloy sheet when accounting for heat conduction[J]. Journal of Materials Processing Technology, 2002, 120(1): 412-418.

[6] NI Jian-li, LI li, LIU Qiang, et al. The Study of Aluminum Alloy Application on Automotive Control Arm[C].// Proceedings of the FISITA 2012 World Automotive Congress. Springer Berlin Heidelberg, 2013: 901-908.

[7] UNGUREANU C A, DAS S, JAWAHIR I S. Life-cycle cost analysis: aluminum versus steel in passenger cars[J]. Aluminium alloys for transportation, packaging, aerospace and other applications, 2007: 11-24.

[8] MOHAMED M S, FOSTER A D, LIN J, et al. Investigation of deformation and failure features in hot stamping of AA6082: Experimentation and modelling[J]. International Journal of Machine Tools and Manufacture, 2012, 53(1): 27-38

[9] MA W, WANG B, FU L, et al. Effect of friction coefficient in deep drawing of AA6111 sheet at elevated temperatures[J]. Transactions of Nonferrous Metals Society of China, 2015,25(7):2342-2351.

[10] FAN Xiao-bo, HE Zhu-bin, YUAN Shi-jian, ZHENG Kai-lun. Experimental investigation on hot forming-quenching integrated process of 6A02 aluminum alloy sheet[J]. Materials Science and Engineering: A, 2013, 573: 154-160.

[11] FAN Xiao-bo, HE Zhu-bin, YUAN Shi-jian, LIN Peng. Investigation on strengthening of $6 A 02$ aluminum alloy sheet in hot forming-quenching integrated process with warm forming-dies[J]. Materials Science and Engineering: A, 2013, 587: 221-227.

[12] Ma W, Wang B, Fu L, et al. Influence of process parameters on deep drawing of AA6111 aluminum alloy at elevated temperatures[J]. Journal of Central South University, 2015,22(4):1167-1174.

[13] MOSHKSAR M M, ZAMANIAN A. Optimization of the tool geometry in the deep drawing of aluminium[J]. Journal of materials processing technology, 1997, 72(3): 363-370. 